\title{
Combined cryoapplications and peritomy in Mooren's ulcer
}

\author{
E. AVIEL \\ Queen Elizabeth Hospital, Blantyre, Malawi
}

Mooren's ulcer is described as a marginal ulceration occurring mainly in elderly people. The ulcer is superficial, has a typically undermined edge, and does not tend to perforate. $\infty$ The course is slowly progressive and eventually the whole cornea may be involved. Pain 을 is an outstanding feature of the condition. The disease may lead to blindness when extensive areas of the cornea are involved. It is bilateral in over a quarter of the cases, but the involvement of both eyes may not be simultaneous. Nothing definite is known about the aetiology of the disease.

Since the condition was first described by Albert Mooren in 1867, various lines of treatment have been tried without great success or uniformity of results (see Bibliography). Cautery, by either chemical or thermal methods, was the procedure traditionally employed. Excision of the ulcer edges and covering of the area with conjunctival flaps has been tried with some measure of success. Peritomy was also tried with temporary relief of symptoms. In recent years lamellar keratoplasty has not proved effective in the treatment of Mooren's ulcer.

This is a report on a small number of cases of Mooren's ulcer in which the course of the disease seems to have been favourably affected by cryoapplications to the ulcer edges combined with peritomy. The cases were diagnosed and treated at the Eye Department of the Queen Elizabeth Central Hospital in Blantyre.

\section{Case reports}

Case r, a female African aged 21 years, was admitted to the Eye Department on March 31 ,, 1970, because of severe pain in the left eye of 4 months' duration. There was no history of trauma $D$ and there had been no previous medications to the eye. The visual acuity was $6 / 7.5$ in the right eye and $6 / 18$ in the left, which was markedly injected. A Mooren's ulcer with a typically under- N mined edge involved almost the whole corneal periphery (Fig. I). Only a small area from 9 to I I $N$ o'clock was free from ulceration. The central part of the cornea was not involved. The right eye was normal.

\section{Treatment}

On April I 7, 1970, cryotherapy of the ulcer edges combined with peritomy was performed on the left eye. The instrument used was the Amoils cryosurgical unit with a cryoprobe tip with an operating temperature of -40 to $-50^{\circ} \mathrm{C}$. Each application was continued for 20 seconds, and the applications were made in the line of both the central and peripheral edges of the ulcer. A peritomy was performed adjacent to the ulcer edges and the bloodvessels reaching the ulcer area were coagulated with heat cautery using a battery-operated instrument. 


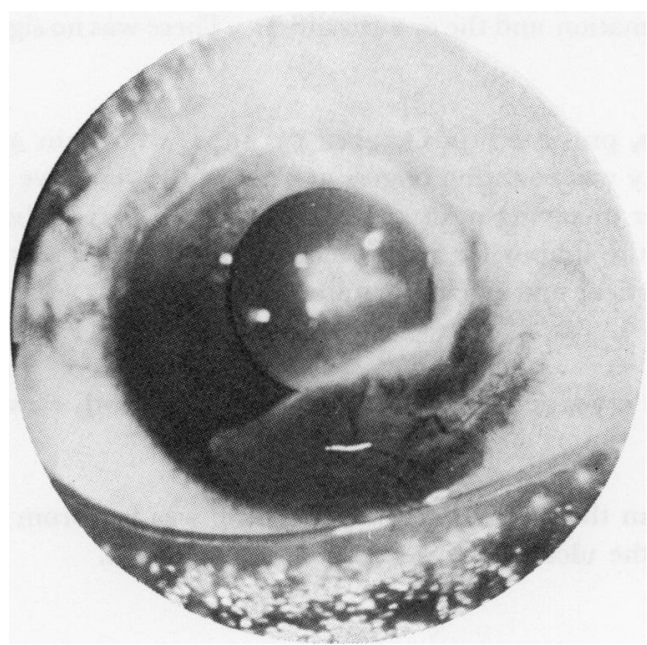

FIG. I Extensive ulceration due to Mooren's ulcer before treatment (Case I)

Result

After 3 days the patient was free from pain. One month later she reported that she had no pain. The vision was unchanged, there was no conjunctival injection, and the ulcer area was scarred, opacified, and smooth. At a subsequent examination 2 months after the operation there was no pain and no evidence of recurrence of the ulcer.

Case 2, a female African aged 47, presented on July 29, 1970, because of pain and defective vision in the left eye of several weeks' duration. From the hospital records it appeared that she had been admitted to the same department Io months previously because of a Mooren's ulcer in the left eye which involved the temporal part of the cornea. The ulcer had been treated with peritomy, and the pain subsided and she was discharged.

On admission in July, 1970, the visual acuity was $6 / 6$ in the right eye and counting fingers at $3 \mathrm{~m}$. in the left. The right eye was normal. The left eye was injected and lacrimating profusely. There was a large superficial ulcer with slightly undermined edges covering more than half the cornea temporally and below.

\section{Treatment}

Cryoapplications and peritomy were performed on the left eye.

Result

4 days later the patient was free from pain. The ulcer area was smoother and appeared to be smaller in size. One month after the operation the patient was free from symptoms and the visual acuity in the left eye was $6 / 36$. The eye was quiet and the scarred ulcer area was smooth and free of blood vessels.

Case 3, a female African aged 18, presented on September 29, 1970, with a complaint of pain and lacrimation of 2 months' duration in the left eye. The visual acuity was $6 / 6$ in the right eye and counting fingers at $2 \mathrm{~m}$. in the left. The right eye was normal. In the left eye there was lacrimation and conjunctival injection. A Mooren's ulcer affected slightly more than half the cornea nasally.

Treatment

Cryoapplications to the ulcer and peritomy were performed on October 9, 1970.

Result

2 weeks later the patient was free from pain, the visual acuity was unchanged, and the conjunctival 
injection had subsided. The ulcer was scarred but smooth. One month after the operation there was no complaint of pain or lacrimation and the eye was quiet. There was no sign of recurrence of the ulcer.

Case 4, a female African aged 50, presented on October 13, 1970, with pain and blurring of vision in both eyes. The visual acuity was counting fingers at $1 \mathrm{~m}$. in the right eye and at $3 \mathrm{~m}$. in the left. There was a Mooren's ulcer involving most of the corneal periphery in both eyes. The ulcer did not extend centrally from the limbus for more than $2 \mathrm{~mm}$. at any point in either eye. There was a progressive posterior cortical and nuclear cataract in both eyes.

\section{Treatment}

On November 5, 1970, peritomy and cryoapplications were performed on both eyes.

\section{Result}

When the patient was discharged from the hospital I week later, she was free from pain, the conjunctival injection had cleared, and the ulcer areas were smooth and healed.

\section{Further Surgery}

On November 26, 1970, an intracapsular cataract extraction was performed on the right eye.

\section{Result}

The postoperative course was uneventful. On December 24, 1970, the patient was discharged from the hospital and the visual acuity in the operated eye was 6/12 with aphakic correction.

\section{Progress}

On January I3, 197 I, the patient presented with a recurrence of pain in the right eye. The corneal ulceration had recurred parallel to the line of the corneo-scleral section for the cataract. Cryoapplications to the ulcer area were repeated, and I week later the pain had subsided and the eye was quiet, the visual acuity remaining unchanged. Since the recurrence of the ulceration the scarring in the right cornea had extended slightly more to the centre, as much as $3 \mathrm{~mm}$. from the limbus.

\section{Result}

At the last examination on May 15, 1971, there was no further complaint of pain, the vision was unchanged, and there was no sign of recurrence of the ulcers (Figs 2 and 3 ).

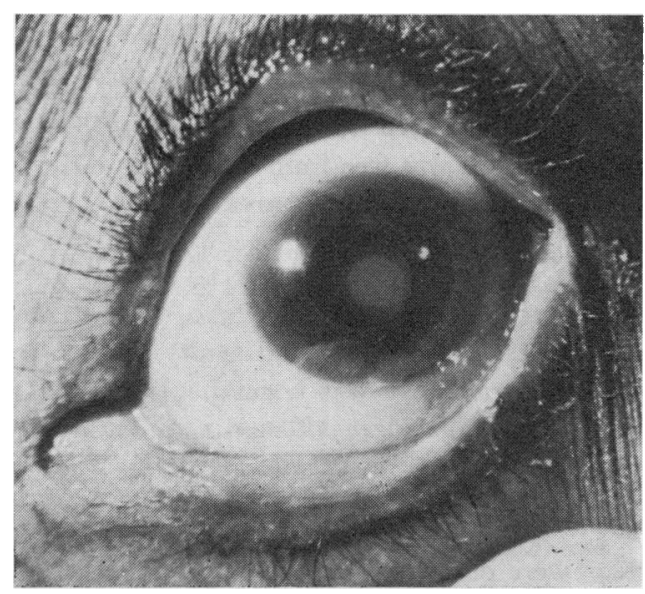

FI G. 2 Left eye 5 months after single cryoapplication and peritomy (Case 4)

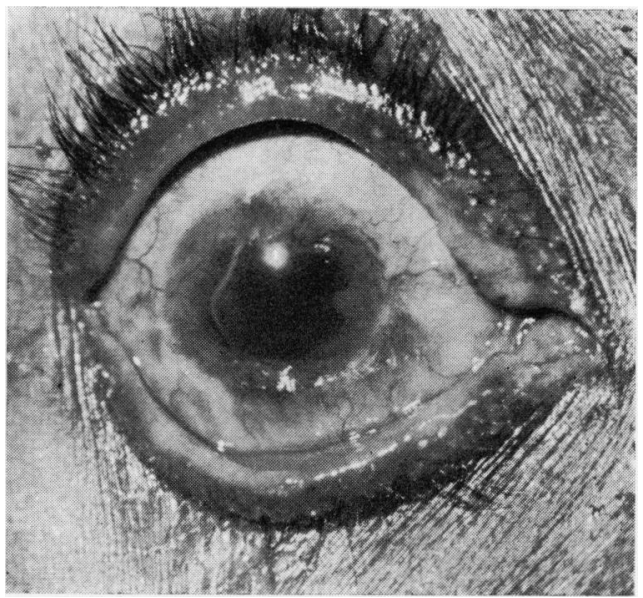

FI G. 3 Right eye 4 months after second cryoapplication (Case 4) 


\section{Comment}

Cryotherapy has been used in herpes keratitis with no ensuing damage to the cornea. In view of the poor results of all other methods of treatment in cases of Mooren's ulcer, it was decided to try cryoapplications to the ulcer edges in conjunction with peritomy.

In all five eyes thus treated there was a rapid improvement in the pain and the eyes quickly became free from inflammation. The eye which underwent a cataract extraction after the first cryoapplication and peritomy had a recurrence of the ulcer in the line of the corneo-scleral section, but this rapidly responded to a fresh series of cryoapplications.

The longest period of follow-up was 5 months. All the patients lived in distant villages and a desirable period of follow-up is frequently impossible in these cases. In our experience, however, the failure of the patients to return for further treatment is often an indication that there has been no recurrence of the complaint. Although it cannot be claimed that a permanent cure was effected, the rapidity and uniformity of the results obtained certainly give the impression of a significant response of the ulcer to the cobined treatment with cryotherapy and peritomy. Little or nothing is known of the pathogenesis of Mooren's ulcer and therefore it is difficult to explain how the improvement in those cases is brought about.

\section{Summary}

Five eyes with Mooren's ulcer of the cornea were treated by peritomy and cryoapplications to the ulcer edges. There was both subjective and objective improvement in all cases over a period of follow-up ranging from $\mathrm{I}$ to 5 months.

\section{Bibliography}

Bellows, J. G. (1966) Eye Ear Nose Thr. Mthly, 45, November, p. 67

DUKE-ELDER, S., and LeIGH, A. G. (1965) "System of Ophthalmology", vol. 8, part 2, p. 9i6.

Kimpton, London

kietzman, B. (I968) Amer. F. Ophthal., 65, 679

KURIAKOSE, E. T. (1963) Ibid., 55, I064

MOOREN, A. (1867) “Ophthalmiatrische Beobachtungen". Hirschwald, Berlin 